\title{
Effect of Carbon Nanotube Size on Compressive Strengths of Nanotube Reinforced Cementitious Composites
}

\author{
Tanvir Manzur, ${ }^{1}$ Nur Yazdani, ${ }^{2}$ and Md. Abul Bashar Emon ${ }^{1}$ \\ ${ }^{1}$ Department of CE, BUET, Dhaka 1000, Bangladesh \\ ${ }^{2}$ Department of CE, University of Texas at Arlington, Arlington, TX 76019, USA
}

Correspondence should be addressed to Tanvir Manzur; tmanzur.buet@gmail.com

Received 3 December 2013; Revised 25 June 2014; Accepted 1 July 2014; Published 17 July 2014

Academic Editor: Hugh J. Byrne

Copyright (C) 2014 Tanvir Manzur et al. This is an open access article distributed under the Creative Commons Attribution License, which permits unrestricted use, distribution, and reproduction in any medium, provided the original work is properly cited.

\begin{abstract}
Application of nanoscale science to construction material has already begun. In recent times, various nanofibers have raised the interest of researchers due to their exceptional mechanical properties and high potential to be used as reinforcement within cement matrix. Carbon nanotube (CNT) is one of the most important areas of research in the field of nanotechnology. The size and exceptional mechanical properties of CNT show their high potential to be used to produce high performance next generation cementitious composites. In this study, an attempt has been made to investigate the effect of size of CNTs on compressive strengths of CNT reinforced cement composites. Seven different sizes of multiwalled nanotubes (MWNTs) were used to produce MWNTcement composites. A trend was observed regarding the effect of nanotube size on compressive strength of composites in most cases. MWNT with outside diameter (OD) of $20 \mathrm{~nm}$ or less exhibited relatively better performance. Smaller MWNT can be distributed at much finer scale and consequently filling the nanopore space within the cement matrix more efficiently. This in turn resulted in stronger composites.
\end{abstract}

\section{Introduction}

In the field of nanotechnology, carbon nanotube (CNT) has the prime focus as one of the most major and significant areas of research. There is particular interest in developing nanotechnology for cement and concrete. Not only the chemistry that forms cement hydration products but also the physical behavior of those products is acquiescent to manipulation through nanotechnology. The mechanical properties of CNT depict their immense potential for use as reinforcements in composite materials. In addition to their high strength and elastic constant, CNTs have extremely high aspect ratios, with values typically higher than 1000:1 and reaching as high as 2,500,000:1 [1]. The size and aspect ratios of CNT mean that they can be distributed on a much finer scale than commonly used reinforcing fibers [1]. Cracks can be interrupted much more quickly during propagation in a CNT reinforced matrix. This bridge coupling effect of CNT in turn assures lower crack widths and eventually guarantees the load transfer across voids and cracks. These mechanical properties of CNT reflect its prospect as reinforcement within the matrix of cementitious composites.

In recent times, various nanofibers have raised the interest of researchers due to their exceptional mechanical properties and high potential to be used as reinforcement within cement matrix. Carbon nanotube (CNT) is one of the most important areas of research in the field of nanotechnology. CNTs have already proven their reinforcing performance in polymer based materials $[2,3]$. The size and exceptional mechanical properties of CNT show their high potential to be used to produce high performance next generation cementitious composites. It has already been found by various researches that addition of nanotubes improved various mechanical properties of cementitious composites. A study by Makar et al. [1] shows that addition of SWNT accelerates the hydration process at early age. Another study by Makar and Chan [4] explained in detail the hydration process of cement reinforced with nanotubes. It was found that presence of nanotubes affected the morphology of cement hydration products, both the initial $\mathrm{C}_{3} \mathrm{~A}$ and the $\mathrm{C}_{3} \mathrm{~S}$ hydration products. It was 
TABLE 1: Properties and composition of untreated MWNTs.

\begin{tabular}{|c|c|c|c|c|c|c|c|}
\hline Types of MWNT and properties & M1 & M2 & M3 & M4 & M5 & M6 & M7 \\
\hline Outside diameter (nm) & $>50$ & $20-30$ & $10-20$ & $<8$ & $8-15$ & $20-40$ & $30-50$ \\
\hline Length $(\mu \mathrm{m})$ & $10-20$ & $10-30$ & $10-30$ & $10-30$ & $10-30$ & $10-30$ & $10-20$ \\
\hline Purity (wt\%) & $>95$ & $>95$ & $>95$ & $>95$ & $>95$ & $>95$ & $>95$ \\
\hline Ash (wt\%) & $<1.5$ & $<1.5$ & $<1.5$ & $<1.5$ & $<1.5$ & $<1.5$ & $<1.5$ \\
\hline Specific surface area, SSA $\left(\mathrm{m}^{2} / \mathrm{g}\right)$ & $>40$ & $>110$ & $>233$ & $>500$ & $>233$ & $>110$ & $>60$ \\
\hline Electrical conductivity, EC (s/cm) & $>10^{-2}$ & $>10^{-2}$ & $>10^{-2}$ & $>10^{-2}$ & $>10^{-2}$ & $>10^{-2}$ & $>10^{-2}$ \\
\hline
\end{tabular}

also observed that CNT accelerated the rate of hydration process by acting as a matrix for the development of C-S-H and $\mathrm{Ca}(\mathrm{OH})_{2}$ produced during the hydration. CNT acts as nucleating agent during cement hydration by providing more sites for the reaction to occur and encourage the formation of reaction products. In CNT reinforced cement composites, the nucleation of the C-S-H on nanotubes slowed the development of C-S-H coating on the surface of cement grains and eventually accelerated the dissolution and nucleation and growth of hydration products as compared to normal cement paste. The performance of nanotubes as nucleating agent has also been observed for other materials like nanodiamonds grown on SWNT [5], zirconium oxide grown on MWNT [6], silicon nitride grown on MWNT [7], calcium carbonate grown on MWNT [8], and so forth. An increase in compressive strengths at early age was obtained by Agullo et al. [9] through the addition of low concentration of MWNT. They [9] also found that composites with medium concentration of nanotubes achieved less compressive strength as compared to normal cement samples at day 28. Li et al. [10] found that an addition of $0.5 \%$ MWNT increased both the 28-day cement mortar compressive and flexural strength as compared to Portland cement composite. Cwirzen et al. [11] obtained an increase of $10 \%$ in flexural strength of MWNT reinforced composites in comparison with plain cement mortar. They [11] also studied 15 different combinations of nanotubes concentration, water content, and admixture amount for compressive strengths and only one combination yielded significant improvement as compared to control samples. The results of the experimental study conducted by KonstaGdoutos et al. [12] show that cement composites reinforced with short and long MWNT exhibited better performance in flexure and Young's modulus as compared to plain cement paste. Addition of MWNTs can also reduce both water sorptivity and coefficient of permeability by improving the microstructure of cementitious material [13]. Therefore, it is evident that addition of nanotubes within cement matrix has potential to produce cementitious composites with improved mechanical properties. However, results of past researches have been quite variable. A recent article by Parveen et al. [14] also shows such inconsistent improvement of mechanical properties of nanotube reinforced cementitious composites for different mixing process and concentration of CNT. It is, therefore, imperative to verify rigorously the effect of different parameters of nanotubes on mechanical properties of nanotubes reinforced cement composites in order to achieve more uniform results. In lieu of this, the effect of nanotubes size on the compressive strength of MWNTcement composites is discussed in this study. Initially, seven different types of commercially available untreated MWNT were used to produce composites. Different mix proportions and concentrations of MWNT were utilized. It was found that size of MWNT influenced the compressive strengths of composites. A particular trend was observed in most of the cases. Four different types of surface treated MWNTs were also used in the later phase of the study. Similar phenomena were also found in case of treated MWNTs reinforced composites.

\section{Material Used}

Ordinary type II Portland cement was used as cementitious material in this study. Special graded sand according to ASTM C109 [15] test requirement was utilized. The seven types of untreated MWNT and their properties and composition are shown in Table 1. Commercially available MWNT were collected in powder form. The homogenous suspension of MWNT is of high importance to achieve the desired level of reinforcement within the composite. However, due to van der Waals forces resulting from large surface area of MWNT, they tend to adhere together and are extremely difficult to separate. Manual stirring of MWNT within water is not suitable to suspend nanotubes as this process is not capable of producing required energy to break the agglomeration of MWNT which in turn produce an unstable mix. Therefore, ultrasonic vibration was utilized to exfoliate and distribute the MWNT bundles across the cement grains. Another effective way to enhance dispersion is functionalization of nanotubes by adding polar impurities like hydroxyl or carboxyl end groups to the outer surface of MWNT. In this method of functionalization, the MWNT is oxidized in a mixture of nitric and sulfuric acids and then the acid treated MWNT is heated and sonicated. This acid treatment results in more soluble nanotubes than pristine CNT. Table 2 provides the properties of surface treated MWNT used in the later phase of the study.

\section{Mixing Method and Experimental Setup}

A MISONIX 4000 sonicator was used for mixing the MWNT within cement matrix. The uniform dispersion of nanotubes is extremely important to achieve adequate reinforcement within the composite. However, as already mentioned, large 
TABle 2: Properties and composition of surface treated MWNTs.

\begin{tabular}{|c|c|c|c|c|}
\hline Types of MWNT and properties & M2 & M3 & M4 & M5 \\
\hline Outside diameter (nm) & $20-30$ & $10-20$ & $<8$ & $8-15$ \\
\hline Length $(\mu \mathrm{m})$ & $10-30$ & $10-30$ & $10-30$ & $10-30$ \\
\hline Purity (wt\%) & $>95$ & $>95$ & $>95$ & $>95$ \\
\hline Ash (wt\%) & $<1.5$ & $<1.5$ & $<1.5$ & $<1.5$ \\
\hline Specific surface area, SSA $\left(\mathrm{m}^{2} / \mathrm{g}\right)$ & $>110$ & $>233$ & $>500$ & $>233$ \\
\hline Electrical conductivity, EC $(\mathrm{s} / \mathrm{cm})$ & $>10^{-2}$ & $>10^{-2}$ & $>10^{-2}$ & $>10^{-2}$ \\
\hline $\mathrm{COOH}$ content $(\mathrm{wt} \%)$ & 1.23 & 2.00 & 3.86 & 2.56 \\
\hline
\end{tabular}

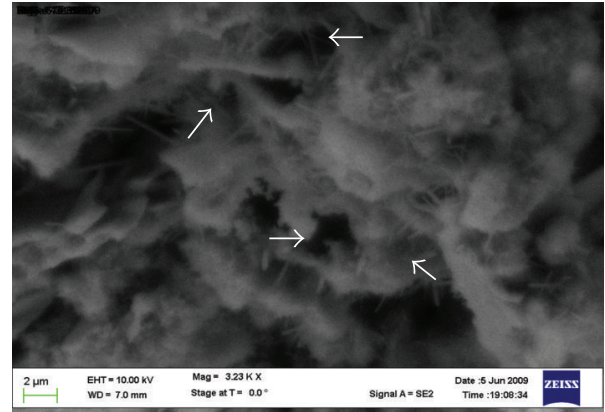

FIGURE 1: SEM images of crushed cement sample (MWNTs are indicated by arrows).

surface area of MWNTs causes high van der Waals forces which in turn results in high tendency of nanotubes to adhere together. Mixing of nanotubes within water by manual stirring is not appropriate and ultrasonic vibration was utilized to distribute the MWNTs across the cement grains. A parametric study regarding sonication was carried out and a suitable technique was suggested [16]. In a typical procedure of this study, MWNT suspension was prepared by sonicating them into water. This water was then used as mixing agent to prepare the composite mortar. SEM images were taken and it was observed that MWNT can be distributed fairly uniformly through the sonication process. Figure 1 shows SEM image of a crushed sample at day 28 .

Compressive strengths of the samples were determined according to ASTM C109 [15]. Cube specimens of $50 \mathrm{~mm}$ size were prepared. The sand to cement ratio was used as $1: 2.75$. A rotary mixer with flat beater was used for mixing. MWNTs were first mixed with water and stirred by hand. Afterwards, sonication was done for 40 minutes in sequence. Cement, sand, and nanotubes were then mixed in the mixer for about 6 minutes as per ASTM C109 requirements. After pouring the mixes into oiled molds $(50 \times 50 \times 50 \mathrm{~mm})$, the specimens were surface smoothed and covered with wet clothes. All the cubes were then kept in the mold for one day in the moisture room and then were demolded and immersed in the lime water until tested. Compressive strength tests were conducted at the ages of 7 and 28 days. An MTS machine was used to apply compressive load on the specimens and the results were obtained through a data acquisition system. The experimental setup for compressive strength test is shown in Figure 2.

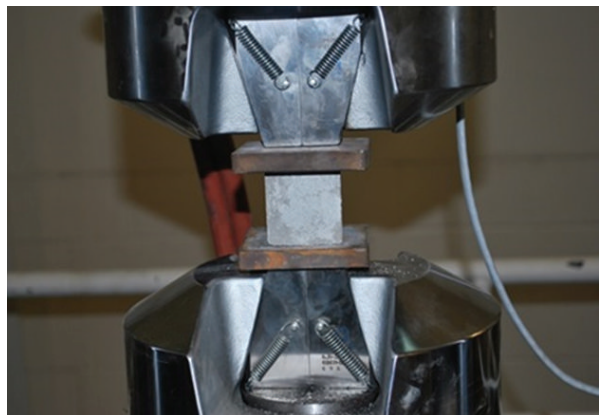

FIGURE 2: Compressive strength test of mortar cube using MTS.

\section{Experimental Results and Discussion}

Both control samples (no MWNT) and composite samples were prepared for testing and comparison purposes. A w/c ratio of 0.485 was initially used to prepare composites. Due to the strong capillary forces of the nanotubes, water was drawn into them, effectively sequestering them from the rest of the mixture and causing workability to decrease. This in turn prevented the fluid cement from completely filling the mold, resulting in large bubbles being trapped in the cement. These bubbles and corresponding voids produced samples with uneven sides and surfaces that significantly reduced the strengths of composites. To avoid this problem, a superplasticizer was used to increase the workability in some cases. Workability of mixes was evaluated through flow table tests [17]. Flow values are good indicator of workability as well as quality of nanotubes dispersion within cement matrix [18]. Also w/c ratio was increased in other cases. Different mix proportions having $\mathrm{w} / \mathrm{c}$ ratio ranging from 0.485 to 0.60 were used. Composites were also made with plasticizer addition keeping w/c ratio at 0.485 . Plasticizer was added to increase the workability of the mixes without increasing the water content. Since no significant effect of plasticizer addition was found on composites' strengths versus size of nanotubes, this part is excluded from the current paper. Seven different types of MWNT based on outside diameter were used in the experiment. It was already mentioned that the diameters ranged between $50 \mathrm{~nm}$ and $8 \mathrm{~nm}$. Samples were then tested at days 7 and 28 to measure the compressive strengths. Control samples were made with w/c ratios of $0.485,0.55$, and 0.60 . Since control samples having w/c ratio of 0.485 


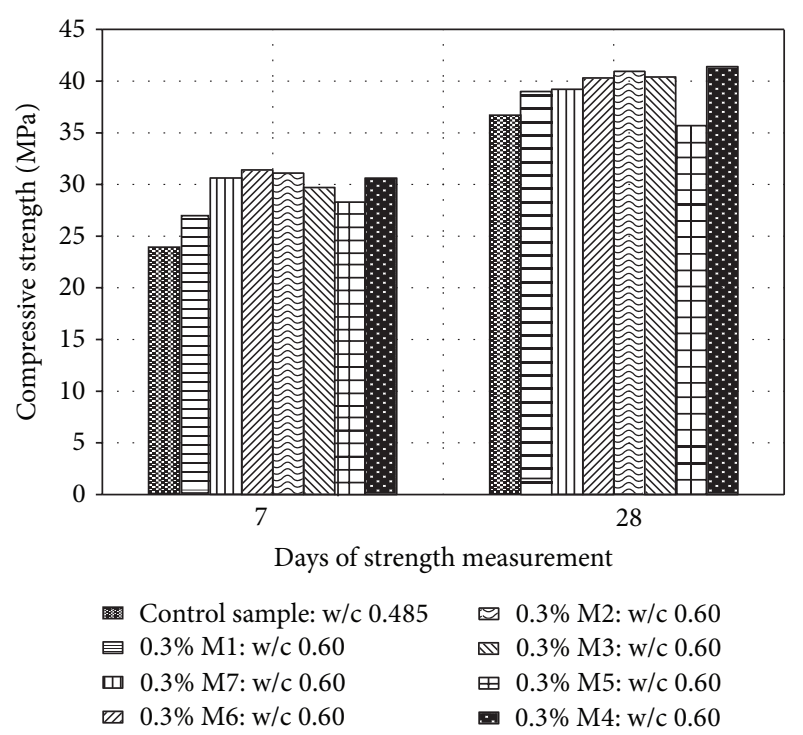

Figure 3: Compressive strength for different 0.3\% MWNT-cement composites with w/c 0.60 .

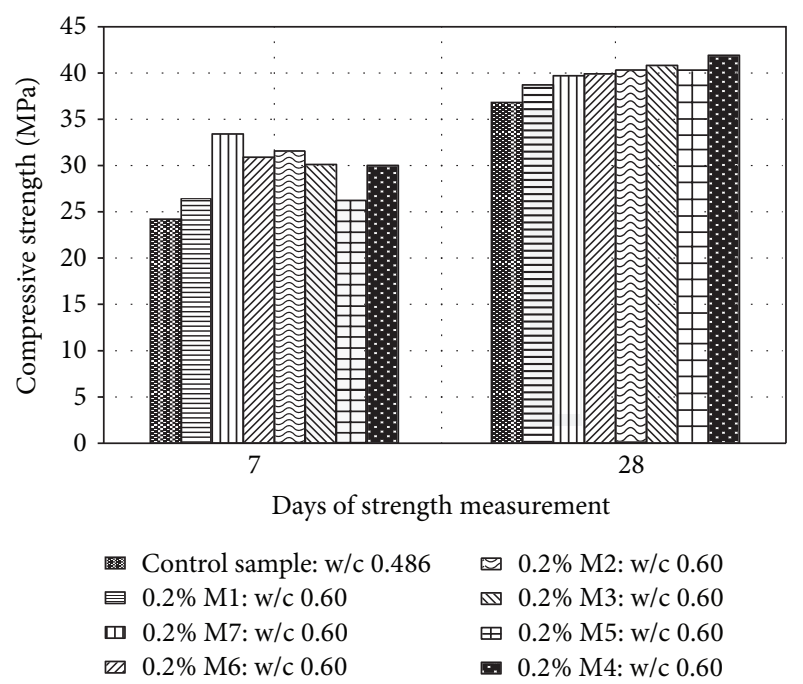

FIgURE 4: Compressive strength for different 0.2\% MWNT-cement composites with w/c 0.60 .

produced the maximum compressive strength both at days 7 and 28, these strengths were used for comparison with composites reinforced by nanotubes. Composites with higher $\mathrm{w} / \mathrm{c}$ (w/c rato of 0.60$)$ achieved higher strengths since more aqueous solution available within these composites provides more spaces for MWNT to disperse through sonication that eventually result in uniform dispersion. Musso et al. [19] also obtained higher strengths by increasing $\mathrm{w} / \mathrm{c}$ ratio from 0.40 to 0.56 for CNT-cement composites.

Figure 3 shows the compressive strengths at days 7 and 28 of $0.3 \%$ MWNT reinforced composites having w/c ratio of 0.60 . It is apparent that the size of nanotubes has significant effect on the compressive strengths of composites. An upward trend in the compressive strength was found

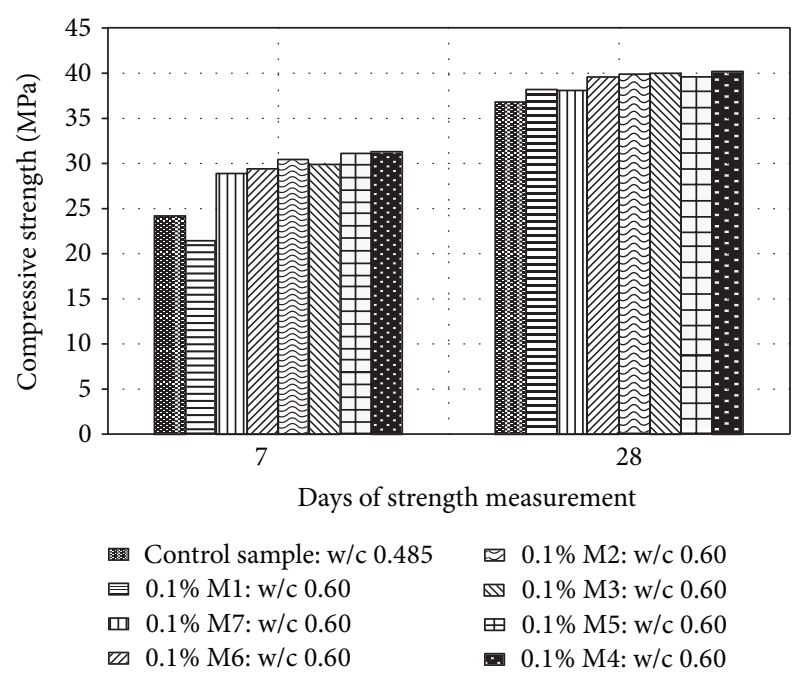

FIGURE 5: Compressive strength for different 0.1\% MWNT-cement composites with w/c 0.60 .

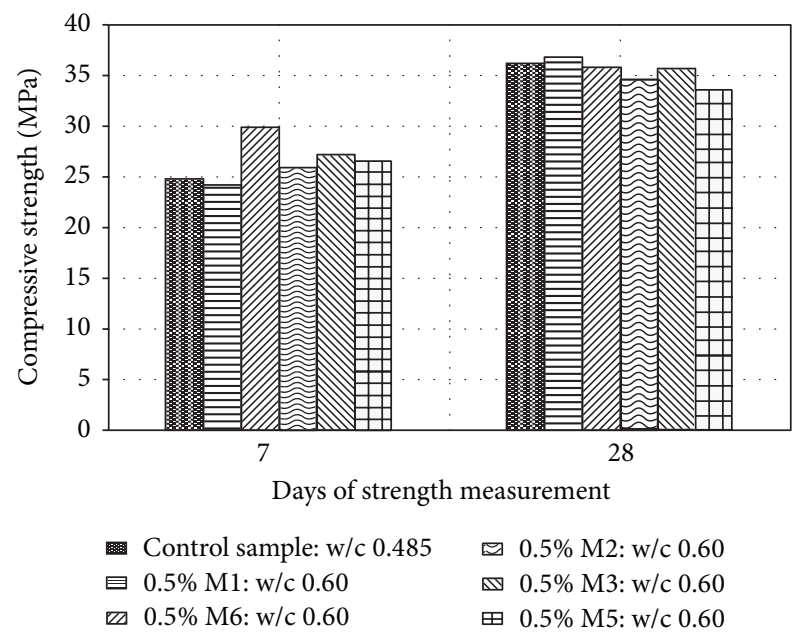

FIGURE 6: Compressive strength for different 0.5\% MWNT-cement composites with w/c 0.60 .

with the decrease in MWNT size. The maximum 28-day compressive strength was achieved by M4 addition which is the smallest in size. Both M1 and M7 produced the lowest compressive strengths at day 28 which was about $5 \%$ less than that of M4-composite. M1 and M7 have the larger outside diameters among the used MWNT. In case of 7-day compressive strength, a slight eccentricity was observed. M1 produced the lowest 7-day compressive strength as in the case of day 28 , but the highest compressive strength was achieved by the addition of M2 and M6. However, the difference between 7-day compressive strengths of M2 and M4 added composites was only $1.5 \%$.

Variations in compressive strengths at the ages of 7 and 28 days for seven different types of MWNT with dosage rates of $0.2 \%, 0.1 \%$, and $0.5 \%$ are provided in Figures 4,5 , and 6 having w/c ratio of 0.60 . It was observed that, with the decrease in MWNT size, an increase in compressive strength 
was achieved for both $0.2 \%$ and $0.1 \%$ of nanotubes addition. This pattern of behavior is predictable and matched with the hypothesis that nanotubes act as nucleating agent during hydration. Therefore, proper sonication of smaller size nanotubes ensures more spaces for hydration products to develop which in turn results in greater amount of high stiffness C-S$\mathrm{H}$ phase. It was also found that composites with nanotubes achieved relatively higher 7-day compressive strengths than 28-day strength, as compared to control samples in all instances. This is due to the fact that presence of nanotubes affects the morphology of both $\mathrm{C}_{3} \mathrm{~A}$ and $\mathrm{C}_{3} \mathrm{~S}$ hydration products at the initial stage and eventually accelerates the hydration process at early stage. For $0.2 \%$ dosage rate, the highest compressive strength was gained by M4 and the minimum compressive strength was attained by $\mathrm{M} 1$ at the age of 28 days. The difference between these two extreme cases is about $8 \%$. Identical phenomena were also observed for $0.1 \%$ concentration of MWNT and the maximum compressive strength was $5 \%$ higher than the lowest one. Similar upward trends in compressive strengths were observed for $0.1 \%$ dosage rate of MWNT at the age of 7 days. In case of $0.2 \%$ dosage rate, the behavior analogues to $0.3 \%$ dosage rate was found. From the obtained test data, it can be inferred that for $0.1 \%, 0.2 \%$, and $0.3 \%$ amount of MWNT addition, the differences in compressive strengths for samples with MWNT having OD between 20 and $8 \mathrm{~nm}$ are minute. It is also observed that the composites producing the maximum 7-day compressive strengths did not always attain the peak strength at the age of 28 days but was able to produce comparable strengths similar to the highest one.

Addition of $0.5 \%$ MWNT in all cases produced compressive strengths lower than that of control samples and no particular trend was evident. It was found that any dosage rate greater than $0.3 \%$ yielded lower compressive strength at the age of 28 days. This is due to inadequate dispersion of MWNT resulting from agglomeration of nanotubes which in turn produces less workable and unstable mixes. It is extremely difficult to attain homogenous distribution of higher amount of nanotubes even with sonication process. In this case of higher dosage rate of nanotubes, it was found that the compressive strength was lower for smaller size of MWNT at day 28. Greater surface area of smaller size MWNT causes more nanotubes to adhere to each other if not properly dispersed and eventually attracts more water on their larger surface areas. Water also gets entrapped within the agglomerated nanotubes. This behavior also suggests that an optimum dosage rate exists to produce desirable composites for a given mixing technique and mix proportion.

In Figures 7, 8, 9, 10, and 11, compressive strengths for samples reinforced with seven different types of MWNT for mix proportions with w/c ratio of 0.55 and 0.485 are shown. For composites containing w/c ratio of 0.55 , a rising trend was found with decreasing size of MWNT having dosage rates of $0.2 \%$ and $0.1 \%$. Dosage rates of $0.3 \%$ MWNT yielded almost equal compressive strengths for M6, M2, and M3 reinforced composites at the ages of both 7 and 28 days. Addition of M4 produced a bit lower compressive strength in this case. No particular trend was observed for dosage rate of $0.3 \%$ with w/c ratio of 0.55 . The workability in this case $(0.3 \%$ dosage rate

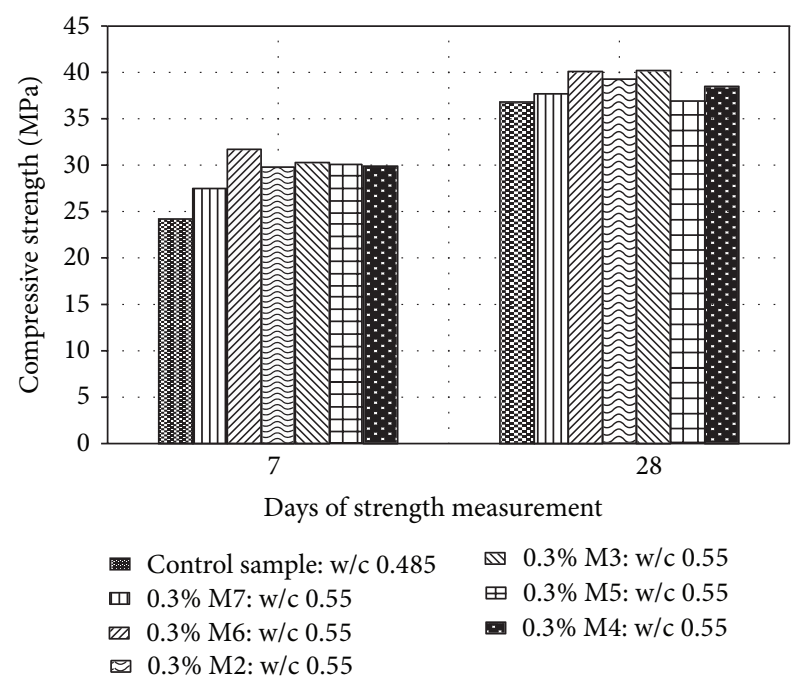

FIGURE 7: Compressive strength for different 0.3\% MWNT-cement composites with w/c 0.55 .

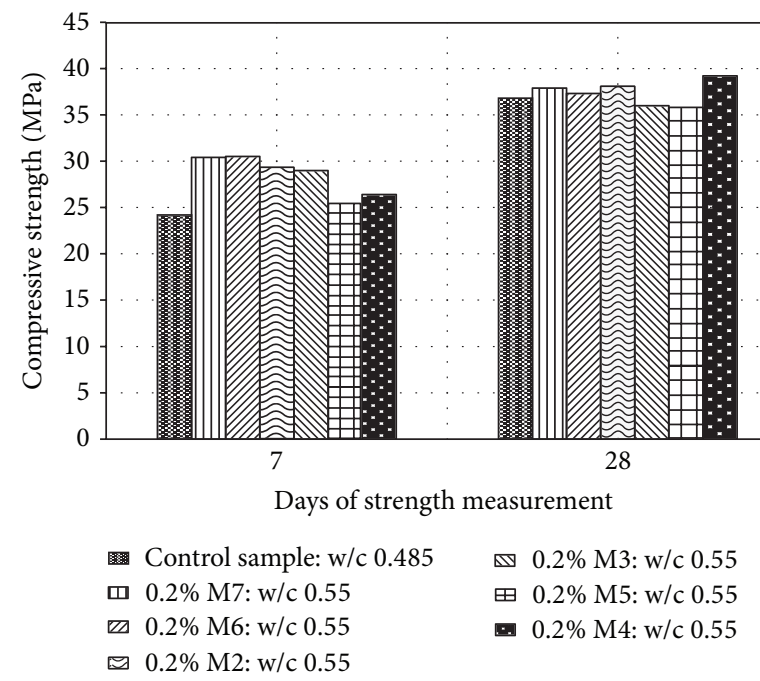

FIGURE 8: Compressive strength for different $0.2 \%$ MWNT-cement composites with w/c 0.55 .

and $\mathrm{w} / \mathrm{c}$ ratio of 0.55 ) was also found as fairly low. Composites having w/c of 0.485 produced lesser compressive strengths than control samples for all dosage rates and, similar to $0.5 \%$ dosage rate with w/c ratio of 0.60 and $0.3 \%$ dosage rate with $\mathrm{w} / \mathrm{c}$ ratio of 0.55 , no definite pattern was apparent. These composites have relatively low workability and in turn fail to achieve sufficient strength. Water was drawn into nanotubes due to the strong capillary forces and effectively sequestering them from the rest of the mixture. This phenomenon caused workability to decrease. Consequently unstable cement mixes are produced with large bubbles being trapped within the mix and eventually resulted in weaker composites. Therefore, adequate amount of water is also required to produce stable composites reinforced with nanotubes. It is therefore obvious that a particular trend is only found when relatively adequate 


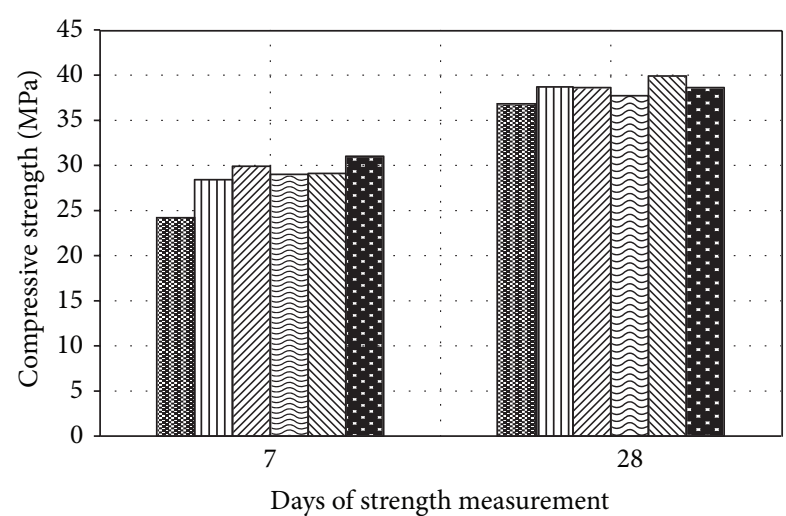

\begin{tabular}{|c|c|}
\hline Control sample: w/c 0.485 & $\varpi 0.1 \% \mathrm{M} 2: \mathrm{w} / \mathrm{c} 0.55$ \\
\hline 四 $0.1 \% \mathrm{M} 7:$ w/c 0.55 & ه $0.1 \% \mathrm{M} 3: \mathrm{w} / \mathrm{c} 0.55$ \\
\hline $0.1 \% \mathrm{M} 6: \mathrm{w} / \mathrm{c} 0.55$ & $0.1 \% \mathrm{~N}$ \\
\hline
\end{tabular}

Figure 9: Compressive strength for different 0.1\% MWNT-cement composites with w/c 0.55 .

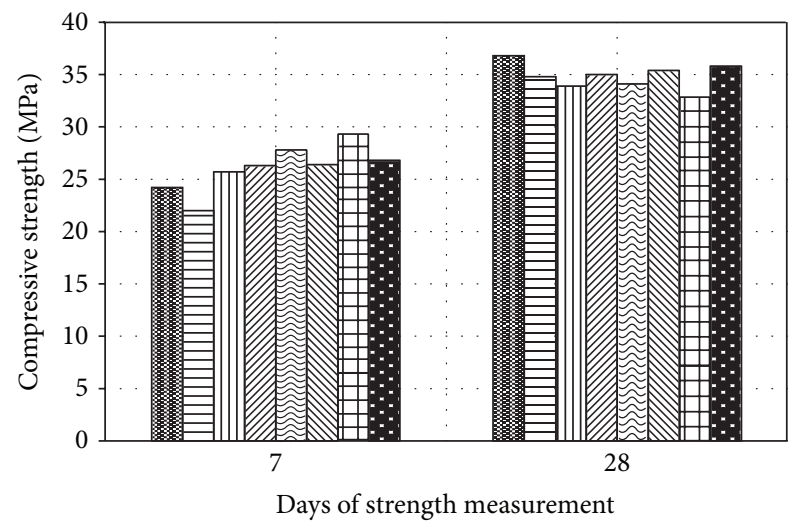

$$
\begin{aligned}
& \text { 圈 Control sample: w/c } 0.485 \\
& \text { 曰 } 0.3 \% \mathrm{M} 1: \mathrm{w} / \mathrm{c} 0.485 \\
& \text { } 0.3 \% \mathrm{M} 7: \mathrm{w} / \mathrm{c} 0.485 \\
& \text { 四 0.3\% M6: w/c } 0.485 \\
& \varpi 0.3 \% \mathrm{M} 2: \mathrm{w} / \mathrm{c} 0.485 \\
& \text { 0.3\% M3: w/c } 0.485 \\
& \boxplus 0.3 \% \mathrm{M} 5: \mathrm{w} / \mathrm{c} 0.485 \\
& \text { - } 0.3 \% \mathrm{M} 4: \mathrm{w} / \mathrm{c} 0.485
\end{aligned}
$$

Figure 10: Compressive strength for different 0.3\% MWNT-cement composites with w/c 0.485 .

dispersion of nanotubes is achieved and relative stable mixes are produced.

From the test data of untreated MWNT reinforced composites, it became obvious that MWNT with OD smaller than $20 \mathrm{~nm}$ resulted in higher compressive strength in comparison with composite reinforced with nanotubes having OD greater than $20-30 \mathrm{~nm}$. Therefore, for later phase of the study, acid treated M2, M3, M4, and M5 were selected as reinforcing agents. Acid treatment is an effective way to enhance dispersion of nanotubes. This functionalization process was done by adding polar impurities like hydroxyl or carboxyl end groups to the outer surface of MWNT. In this method of functionalization, the MWNT was oxidized in a mixture of nitric and sulfuric acids and then the acid treated MWNT was heated and sonicated. This acid treatment resulted in more soluble nanotubes than pristine CNT. Mix proportion

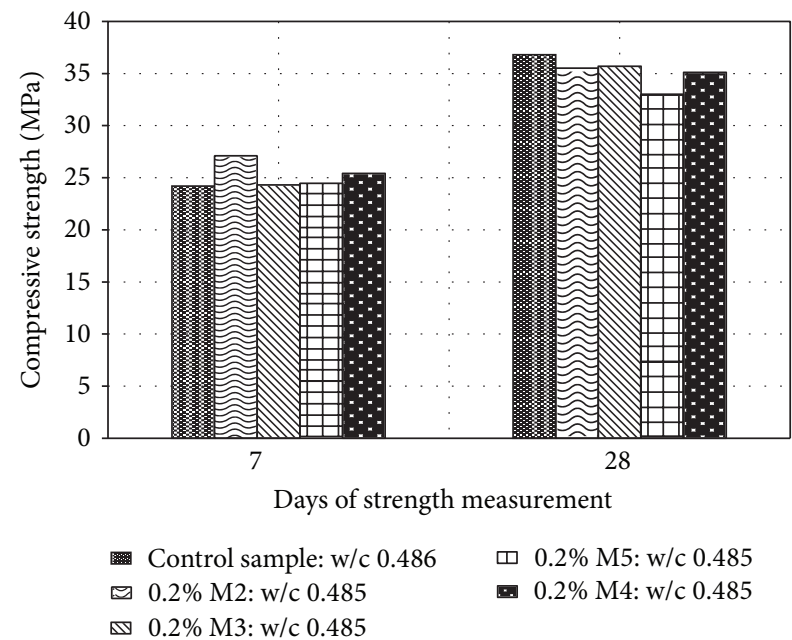

FIGURE 11: Compressive strength for different 0.2\% MWNT-cement composites with w/c 0.485 .

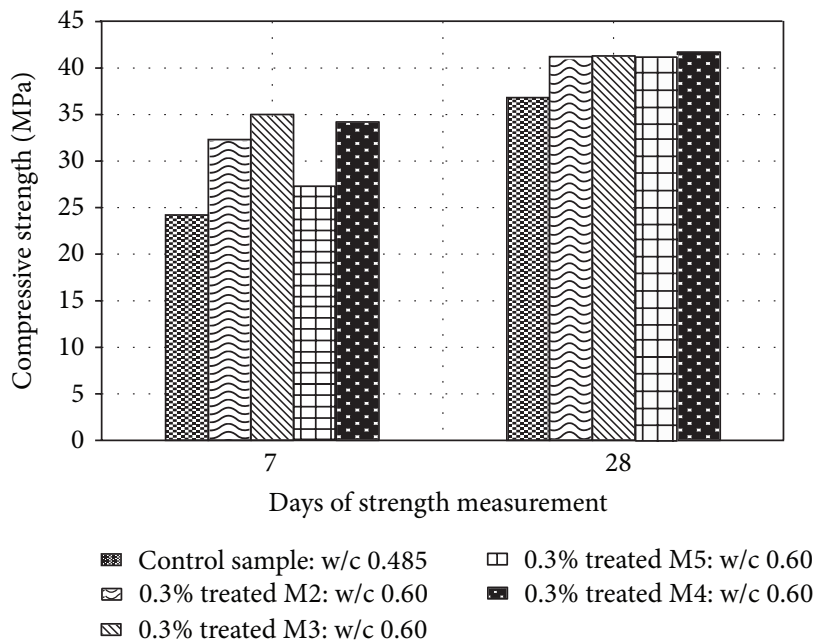

Figure 12: Compressive strength of different acid treated $0.3 \%$ MWNT reinforced composites with w/c ratio of 0.60 .

containing w/c ratio of 0.60 was selected as it yielded relatively higher compressive strength in majority of cases of untreated MWNT composites. Three dosage rates of $0.3 \%$, $0.2 \%$, and $0.1 \%$ were utilized based on the previous results.

In Figure 12, the compressive strengths of $0.3 \%$ surface treated M2, M3, M4, and M5 reinforced composites at the ages of 7 and 28 days are presented. In all cases, w/c ratio was kept at 0.60 . At day 28, all four MWNT added composites produced similar compressive strengths, though some deviations were observed at day 7. The highest compressive strength was achieved by M4 reinforced composites at day 28 (about 13\% higher than the control samples). For M3 addition, this increment was a little greater than $12 \%$. At the age of 7 days, the highest compressive strength was achieved by $\mathrm{M} 3$ addition. Compressive strengths of composites with 0.2 dosage rate of four different sizes of treated MWNT are 


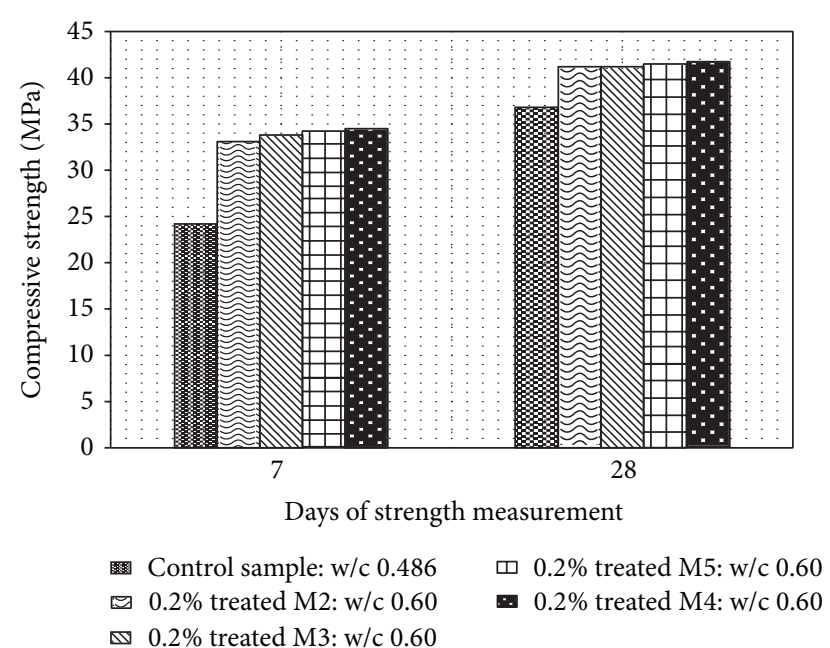

FIGURE 13: Compressive strength of different acid treated $0.2 \%$ MWNT reinforced composites with w/c ratio of 0.60 .

shown in Figure 13. Relatively greater compressive strengths were achieved at day 7 than that of day 28 , as compared to control samples. Identical compressive strengths were obtained at day 28 for $0.2 \%$ addition of M2, M3 , and M5 added composites, which was about $11.5 \%$ higher than that of control samples. Similar pattern was also observed for $0.1 \%$ dosage rate of treated MWNTs.

\section{Conclusions}

The effect of various nanotubes size was investigated in the present work in terms of compressive strengths. A trend was observed in most of the cases. It has been found that MWNT with OD $20 \mathrm{~nm}$ or less obtained similar compressive strengths, with the highest compressive strength being achieved by the smallest size of MWNT having OD smaller than $8 \mathrm{~nm}$ in majority of cases. The minimum compressive strength was obtained by the composites reinforced with the largest nanotubes. Smaller MWNTs are distributed at much finer scale and consequently filling the nanopore space within the cement matrix more efficiently. In addition, they act as nucleating agent during cement hydration and encourage the formation of higher stiffness C-S-H phase. Also, more interfacial bonding can be achieved between nanotubes and cement matrix. Therefore, it can be concluded that smaller MWNT has beneficial effect on the strength properties of cementitious mortar. It was also observed that mixes with low workability failed to achieve any particular pattern of behavior and mostly these composites yielded no significant increase in compressive strengths. Moreover, in some instances, the compressive strengths were less than that of control samples. Less workability reflects inadequate dispersion of nanotubes and it is apparent that the trend of strength increment with the decrease in nanotube size was only observed when fairly adequate distribution of nanotubes was achieved within the cement matrix. Similar pattern was observed in cases of treated MWNTs. It was also found that composites with treated MWNT yielded higher compressive strengths than that of untreated ones. Acid treatment makes the MWNT more soluble to the solution by hindering their agglomeration. As a result, MWNT can be uniformly dispersed and eventually produced strong composites. Therefore, it became obvious that dispersion of nanotubes was the key to develop nanotubes reinforced cement composites.

\section{Conflict of Interests}

The authors declare that there is no conflict of interests regarding the publication of this paper.

\section{References}

[1] J. Makar, J. Margeson, and J. Luh, "Carbon nanotube/cement composites-early results and potential application," in Proceedings of the 3rd International Conference on Construction Materials: Performance, Innovations and Structural Implications, pp. 1-10, Vancouver, Canada, August 2005.

[2] B. Marrs, R. Andrews, and D. Pienkowski, "Multiwall carbon nanotubes enhance the fatigue performance of physiologically maintained methyl methacrylate-styrene copolymer," Carbon, vol. 45, no. 10, pp. 2098-2104, 2007.

[3] Y. Wang, Z. Iqbal, and S. Mitra, "Rapidly functionalized, waterdispersed carbon nanotubes at high concentration," Journal of the American Chemical Society, vol. 128, no. 1, pp. 95-99, 2006.

[4] J. M. Makar and G. W. Chan, "Growth of cement hydration products on single-walled carbon nanotubes," Journal of the American Ceramic Society, vol. 92, no. 6, pp. 1303-1310, 2009.

[5] M. L. Terranova, S. Orlanducci, A. Fiori et al., "Controlled evolution of carbon nanotubes coated by nanodiamond: the realization of a new class of hybrid nanomaterials," Chemistry of Materials, vol. 17, pp. 3214-3220, 2005.

[6] F. Lupo, R. Kamalakaran, C. Scheu, N. Grobert, and M. Rühle, "Microstructural investigations on zirconium oxide-carbon nanotube composites synthesized by hydrothermal crystallization," Carbon, vol. 42, no. 10, pp. 1995-1999, 2004.

[7] C. S. Balázsi, F. Wéber, Z. S. Kövér et al., "Application of carbon nanotubes to silicon nitride matrix reinforcements," Current Applied Physics, vol. 6, pp. 124-130, 2006.

[8] D. Tasis, S. Pispas, C. Galiotis, and N. Bouropoulos, "Growth of calcium carbonate on non-covalently modified carbon nanotubes," Materials Letters, vol. 61, no. 28, pp. 5044-5046, 2007.

[9] V. J. Agullo, V. C. Ligero, D. P. Rico et al., "Mortar and concrete reinforced with nanomaterials," Nanotechnology in Construction, vol. 3, pp. 383-388, 2009.

[10] G. Y. Li, P. M. Wang, and X. Zhao, "Mechanical behavior and microstructure of cement composites incorporating surfacetreated multi-walled carbon nanotubes," Journal of Cement \& Concrete Composites, vol. 43, no. 6, pp. 1239-1245, 2005.

[11] A. Cwirzen, K. Habermehl-Cwirzen, and V. Penttala, "Surface decoration of carbon nanotubes and mechanical properties of cement/carbon nanotube composites," Advances in Cement Research, vol. 20, no. 2, pp. 65-73, 2008.

[12] M. S. Konsta-Gdoutos, Z. S. Metaxa, and S. P. Shah, "Highly dispersed carbon nanotube reinforced cement based materials," Cement and Concrete Research, vol. 40, no. 7, pp. 1052-1059, 2010. 
[13] B. Han, Z. Yang, X. Shi, and X. Yu, "Transport properties of carbon-nanotube/cement composites," Journal of Materials Engineering and Performance, vol. 22, no. 1, pp. 184-189, 2013.

[14] S. Parveen, S. Rana, and R. Fangueiro, "A review on nanomaterial dispersion, microstructure, and mechanical properties of carbon nanotube and nanofiber reinforced cementitious composites," Journal of Nanomaterials, vol. 2013, Article ID 710175, 19 pages, 2013.

[15] American Society for Standard Testing and Materials (ASTM), Standard Test Method for Compressive Strength of HydraulicCement Mortars, ASTM C 109-07, ASTM, West Conshohocken, $\mathrm{Pa}, \mathrm{USA}, 2008$.

[16] T. Manzur and N. Yazdani, "Strength enhancement of cement mortar with carbon nanotubes: early results and potential," Transportation Research Record, no. 2142, pp. 102-108, 2010.

[17] American Society for Standard Testing and Materials (ASTM), "Standard test method for flow of hydraulic cement mortar," Tech. Rep. ASTM C 1437-07, West Conshohocken, Penn, USA, 2008.

[18] T. Manzur and N. Yazdani, "Importance of flow values in qualitative evaluation of carbon nanotube reinforced cementitious matrix," Malaysian Journal of Civil Engineering, vol. 25, no. 1, pp. 72-81, 2013.

[19] S. Musso, J.-M. Tulliani, G. Ferro, and A. Tagliaferro, "Influence of carbon nanotubes structure on the mechanical behavior of cement composites," Composites Science and Technology, vol. 69, no. 11-12, pp. 1985-1990, 2009. 

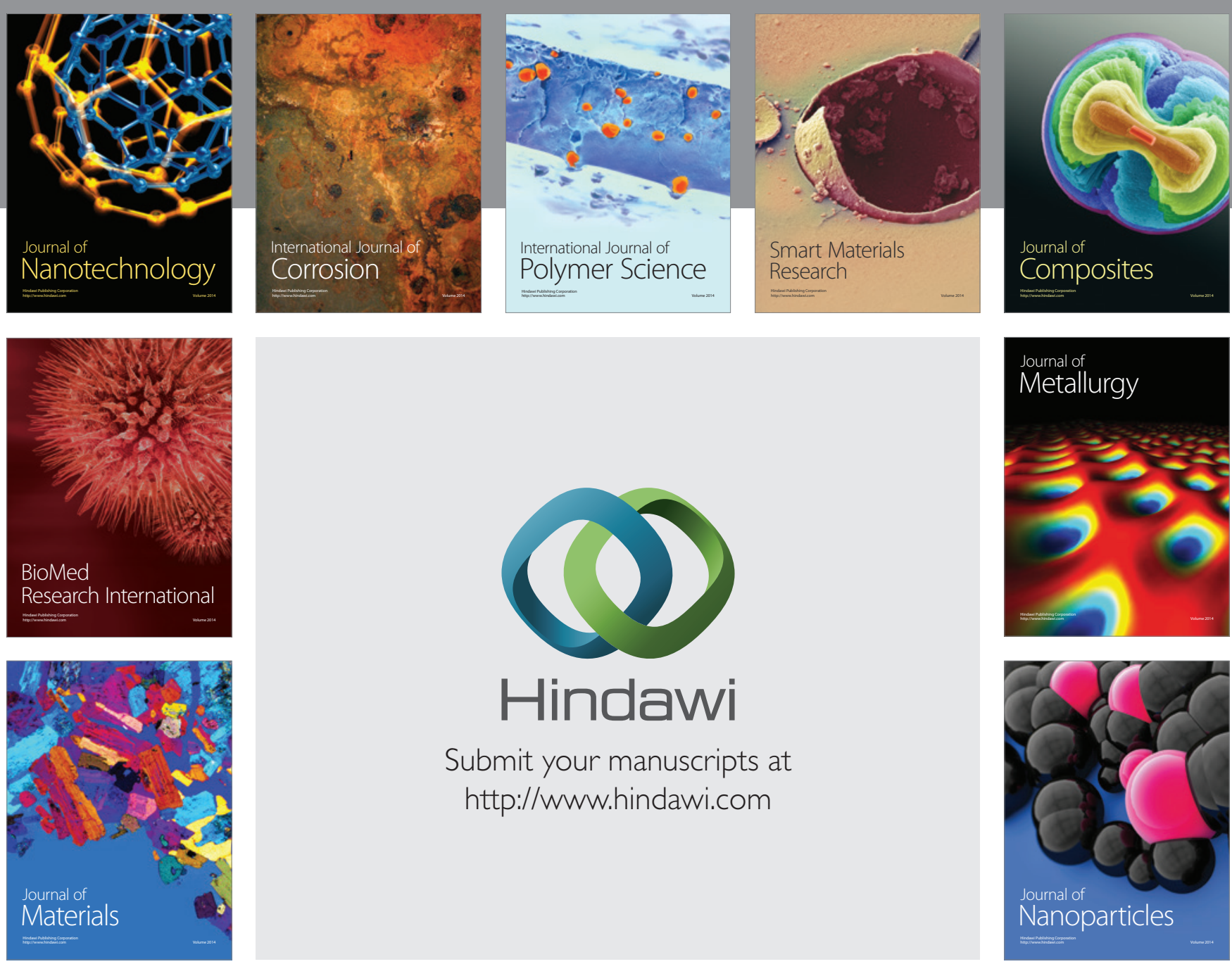

Submit your manuscripts at http://www.hindawi.com
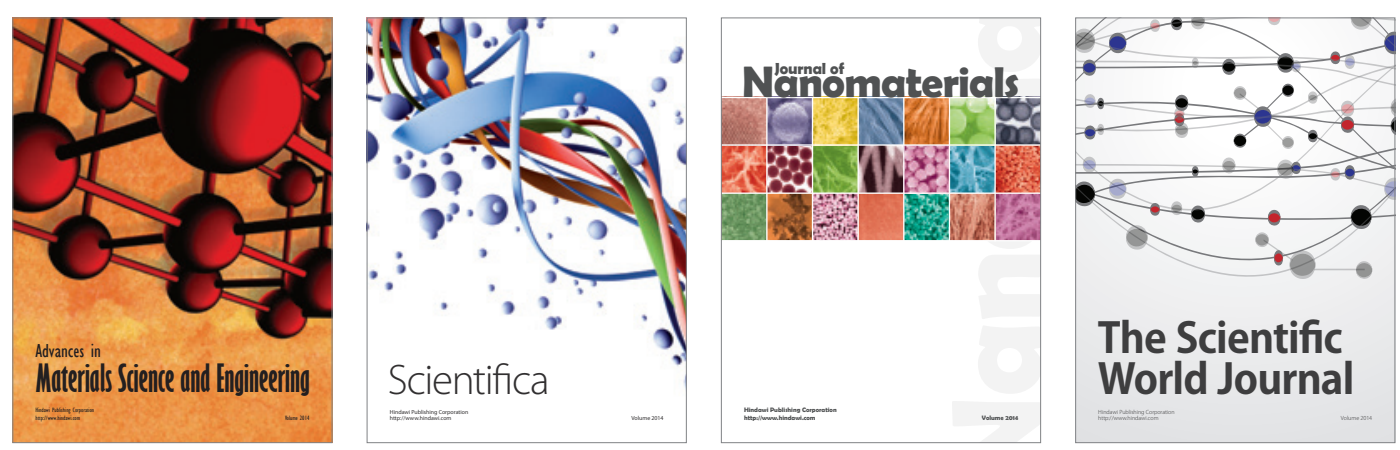

\section{The Scientific World Journal}
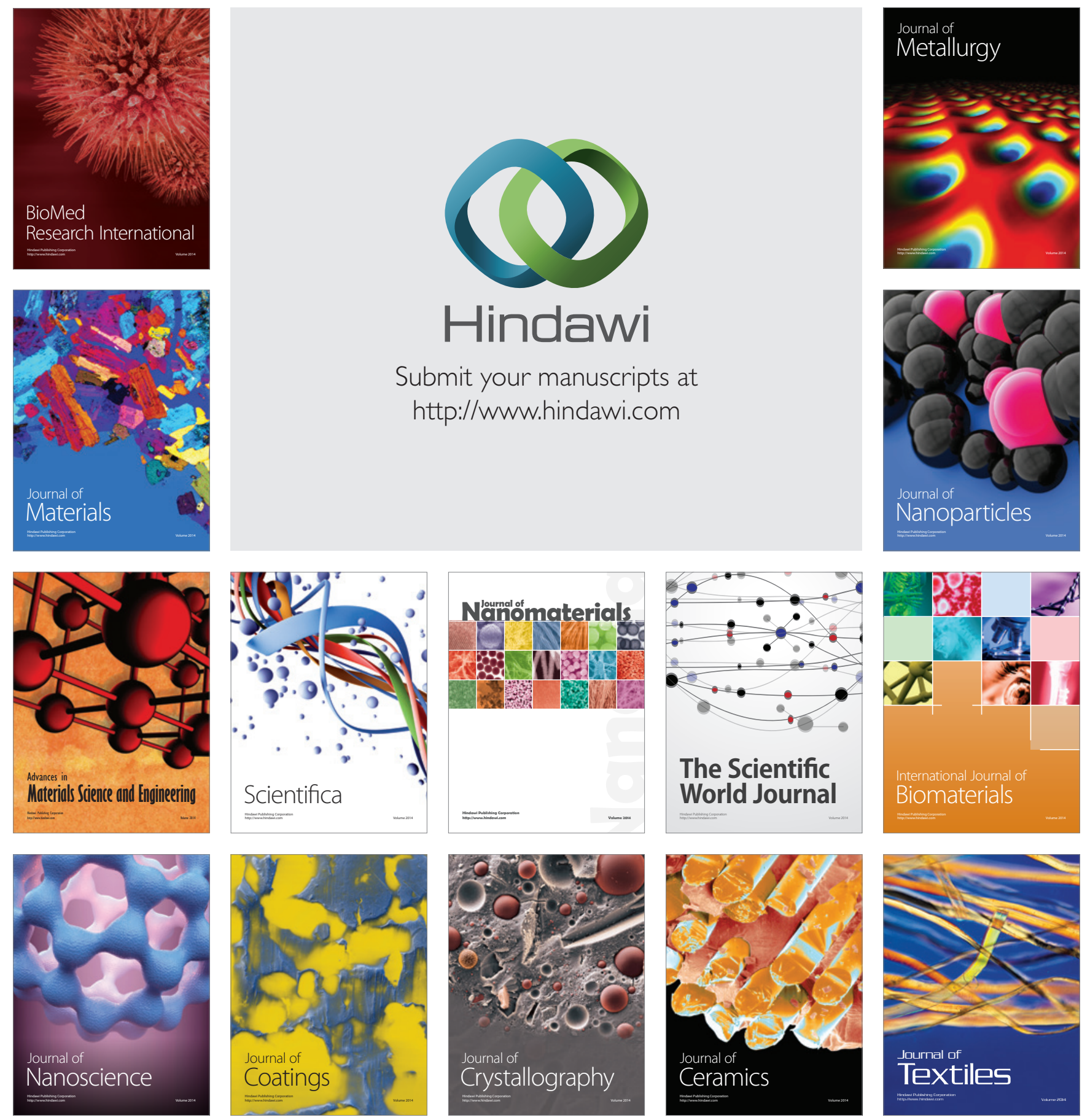